\title{
Rationale, design and methods for a randomised and controlled trial of the impact of virtual reality games on motor competence, physical activity, and mental health in children with developmental coordination disorder
}

\author{
Leon M Straker ${ }^{1,2^{*}}$, Amity C Campbell ${ }^{1,2}$, Lyn M Jensen ${ }^{1,2}$, Deborah R Metcalf ${ }^{1,2}$, Anne J Smith ${ }^{1,2}$,
}

Rebecca A Abbott ${ }^{4}$, Clare M Pollock ${ }^{2,3}$ and Jan P Piek ${ }^{2,3}$

\begin{abstract}
Background: A healthy start to life requires adequate motor development and physical activity participation. Currently $5-15 \%$ of children have impaired motor development without any obvious disorder. These children are at greater risk of obesity, musculoskeletal disorders, low social confidence and poor mental health. Traditional electronic game use may impact on motor development and physical activity creating a vicious cycle. However new virtual reality (VR) game interfaces may provide motor experiences that enhance motor development and lead to an increase in motor coordination and better physical activity and mental health outcomes. VR games are beginning to be used for rehabilitation, however there is no reported trial of the impact of these games on motor coordination in children with developmental coordination disorder.

Methods: This cross-over randomised and controlled trial will examine whether motor coordination is enhanced by access to active electronic games and whether daily activity, attitudes to physical activity and mental health are also enhanced. Thirty children aged $10-12$ years with poor motor coordination $\left(\leq 15^{\text {th }}\right.$ percentile) will be recruited and randomised to a balanced ordering of 'no active electronic games' and 'active electronic games'. Each child will participate in both conditions for 16 weeks, and be assessed prior to participation and at the end of each condition. The primary outcome is motor coordination, assessed by kinematic and kinetic motion analysis laboratory measures. Physical activity and sedentary behaviour will be assessed by accelerometry, coordination in daily life by parent report questionnaire and attitudes to physical activity, self-confidence, anxiety and depressed mood will be assessed by self report questionnaire. A sample of 30 will provide a power of $>0.9$ for detecting a 5 point difference in motor coordination on the MABC-2 TIS scale (mean 17, sd = 5).
\end{abstract}

Discussion: This is the first trial to examine the impact of new virtual reality games on motor coordination in children with developmental coordination disorder. The findings will provide critical information to understand whether these electronic games can be used to have a positive impact on the physical and mental health of these children. Given the importance of adequate motor coordination, physical activity and mental health in childhood, this project can inform interventions which could have a profound impact on the long term health of this group of children.

Trial registration: Australia and New Zealand Clinical Trials Register (ANZCTR): ACTRN12611000400965

\footnotetext{
* Correspondence: L.Straker@curtin.edu.au

${ }^{1}$ School of Physiotherapy, Curtin University, Perth, Australia

Full list of author information is available at the end of the article
} 


\section{Background}

\section{Computer use by children is a major change in our society}

Nearly all Australian children now use computers and video games [1]. More than $79 \%$ of households with children have a computer and more than $60 \%$ have a video game machine [2]. A recent meta analysis of studies in affluent countries found boys' and girls' mean computer/ video game use was 74 minutes a day [3]. Electronic game use is increasing rapidly, with Roberts et al. [4] reporting a doubling since the meta analysis studies.

In a recent review we [5] reported that the available evidence suggested computer use targeted on learning areas is associated with enhanced academic achievement (e.g. [6]) but that electronic game playing has a negative effect on school achievement [7]. We also found that game-related discourse may provide a stimulus for children's social development [8], although there are concerns about the potential negative effects of violence in electronic games [9].

Research on the impact of computer use on children's physical development has focused on postures during computer use at school [10], use of laptop computers [11] and the impact of workstation design on posture and muscle activity [12]. Whilst this research has suggested potential musculoskeletal problems associated with prolonged and constrained postures and repetitive small movements, there is no evidence available on the impact of computer or electronic game use on motor development. We have raised concerns that electronic game use may have a negative impact on gross motor development as it may displace other childhood leisure activities which provide critical practice of gross motor tasks and which facilitate motor development [5].

\section{Electronic game use may have a negative impact on normal motor development}

Normal motor development requires maturation of neural and muscular systems plus the opportunity to practise fine and gross motor skills, with studies on children with impoverished or enriched motor environments providing evidence for the importance of practice [13]. Gross motor experiences are usually associated with physical activity (PA) (defined as the movement of the limbs and torso by muscle activity resulting in energy expenditure). There is evidence that increased PA can provide the practice necessary to improve gross motor skill development in children with normal motor development [14]. However there are concerns amongst researchers and parents that electronic game playing reduces children's PA.

Traditional electronic game interfaces can provide motor experience, but fine rather than gross. Yuji [15] reported evidence that electronic games improved children's fine motor performance. In a review, Whitcomb
[16] found electronic game playing lead to enhanced eye-hand coordination, dexterity and fine motor ability and increased reaction and movement speeds in elderly subjects and Rosser et al. [17] found a dose response relationship between video game experience and laproscopic surgery training performance (both speed and accuracy).

In contrast, traditional electronic game playing probably does not provide gross motor experience, and may lead to a decline in gross motor skill. In an epidemiological study of 1,600 five-year-olds we found that computer use did displace vigorous PA on weekends reducing overall gross motor experience [18] and suggesting a potential vicious cycle.

\section{Children with DCD are at greater risk}

Five to $15 \%$ of children have developmental coordination disorder (DCD), defined as lacking developmental, age-appropriate motor skills, and characterised by motor performance impairment that creates functional performance deficits not likely to be due the child's age, intellect, or other diagnosable neurological or psychiatric disorder $[19,20]$. Underlying deficits identified in children with DCD include poor sensory-motor integration [21] and in particular, poor visuomotor processing [22], or cross-modal integration (visual-kinaesthetic). Children with DCD also have poor timing and force control and it has been argued that there may be a disruption in the central timing mechanisms, usually linked with cerebellar function [23]. A recent review found that these children are less physically active and have lower levels of fitness [24]. Children with DCD are thus at greater risk of insufficient PA [25] and a downward spiral of poorer motor development, psychological and health outcomes (Figure 1).

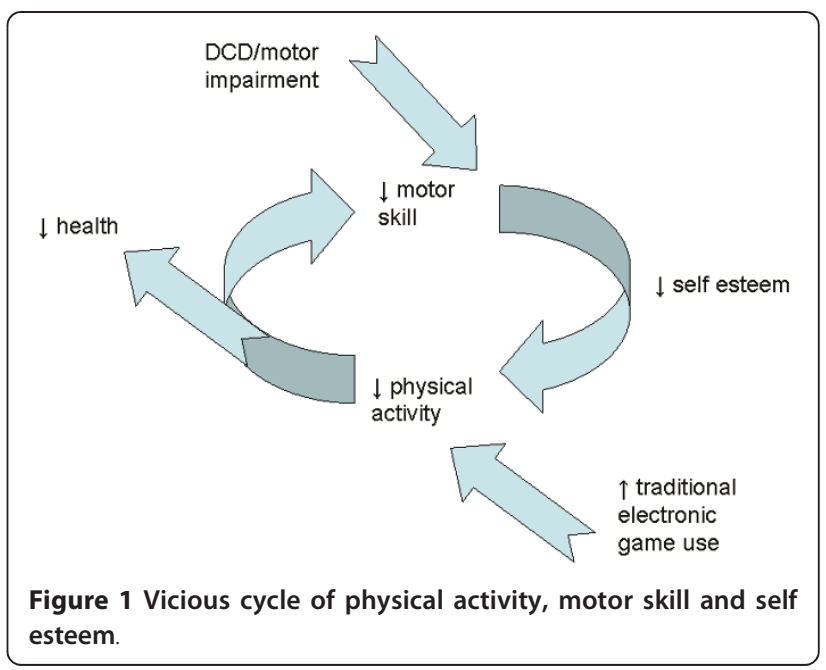


Motor skill can be improved in children with DCD

Whilst there are varying views as to the underlying pathology of DCD and no consensus on the correct approach to intervention, a recent review concluded that there is sufficient evidence of good quality to confirm that interventions are effective in improving motor skill in children with DCD [26]. Approaches ranging from perceptual-motor therapy, to sensory-integration therapy, mastery and physiotherapy are supported with little evidence of the superiority of any specific approach [26], although studies were of variable quality. Intervention doses range from 30 minutes weekly for 6 weeks [27] to 50 minutes 3 times a week for 10 weeks [28].

Motor skill is important for physical activity participation Children need to have a certain degree of motor skill to feel confident to engage in PA. Harter's $[29,30]$ competence motivation theory argues that children's motivation to engage in an activity (in this case, PA) is determined partly by the confidence they have in their ability to carry out these tasks. Hence, children who are more skilled would be more likely to engage in the activity. According to Doganis and Theordarakis [31], attitude theory best explains engagement in PA and sport. It is considered to comprise three elements, namely cognitive, affective and behavioural. A child's perception of their own ability is one component of the cognitive element. Their enjoyment of the activity, or the anxiety it generates, are part of the affective element. The behaviour component relates to the outcomes, good or bad, of participation and its reinforcement qualities. Therefore a vicious circle may develop for children where reduced PA results in reduced motor skill which further impedes PA participation.

\section{Physical activity is important for health and development} Over $80 \%$ of Australian children do not meet national standards for adequate PA [32]. A lack of adequate PA has been linked with childhood health issues including obesity, bone mineral density, type II diabetes and cardiovascular risk factors [25,33]. Boys with DCD appear to be at greater risk of obesity [34].

Children with DCD have been found to engage less in PA than other children [25]. More recently Poulsen et al. [35] found a negative correlation between DCD and participation in social PA. It has been suggested that this is due to the fact that children with DCD do not like to display their poorer athletic skill to their peers [34], in line with Harter's [29,30] competence motivation theory. Our research [36] has demonstrated that children with DCD perceive themselves as poorer in the domain of athletic competence, and this has been linked to high levels of anxiety [37] and depressive symptomatology [38]. In line with attitude theory, this negative affect would then impact on the child's future interest in engaging in PA.

\section{Electronic games have traditionally been sedentary}

Electronic games have traditionally used keyboard/mouse and game pad interfaces which require very little movement. In a laboratory study of children with normal motor development we found energy expenditure during traditional electronic game playing to be similar to watching a DVD [39]. We also found minimal levels of muscle activity and movement during traditional electronic game playing [40]. Whilst traditional electronic games may have some positive physical impact on fine motor skills this may be offset by decreasing overall PA levels and reduced gross motor practice. Poorer PA outcomes may be associated with lower activity during actual game playing and by the displacement of more active leisure activities. Reduced gross motor practice may lead to poorer motor development. Whilst Li and Atkins [41] found some evidence of a relationship between poorer gross motor ability and increasing computer use in pre schoolers there is no direct evidence on the link between electronic games and poorer motor skills.

Marshall et al. [42] reviewed available studies and found 10 cross sectional studies showing a weak negative relationship ( $r=-0.14$ ) between electronic games/computer use and PA. However the nature of computer use was not specified so included games and other uses. Recent reviews have included longitudinal studies and have also questioned whether electronic game use displaces more vigorous PA $[43,44]$. Despite no experimental evidence of a causal effect of electronic games on motor development, attitudes to PA or overall PA there is considerable community concern.

In a recent pilot study with 12 children (6 with DCD) [45] we found access to traditional electronic games for 8 weeks resulted in a trend for a $23.1 \%$ reduction in accelerometer assessed energy expenditure on non school days $(\mathrm{p}=.122)$ and significant reductions in both motor competence (McCarron Assessment of Neuromotor Disorders Neurodevelopmental Index [46] 7.3\% p = .044) and liking of physical activity [47] $(6.0 \% \mathrm{p}=.048)$ compared to an 8 week period when electronic games were removed from the house of children with DCD (see Figure 2).

\section{New opportunities with active virtual reality games}

Virtual reality (VR) refers to a simulated interactive environment. VR aims to create a visual, auditory and sometimes tactile and olfactory environment that appears real and enables the human user to become immersed in the interactive experience. VR has been extensively used in commercial/military training applications such as flight and surgery simulators. It has also been used for arcade games and recently for patient rehabilitation. Until recently the only VR systems were expensive $(\$ 100,000+)$ laboratory based systems or large dedicated leisure simulators. However cheap $(<\$ 500)$ VR systems 


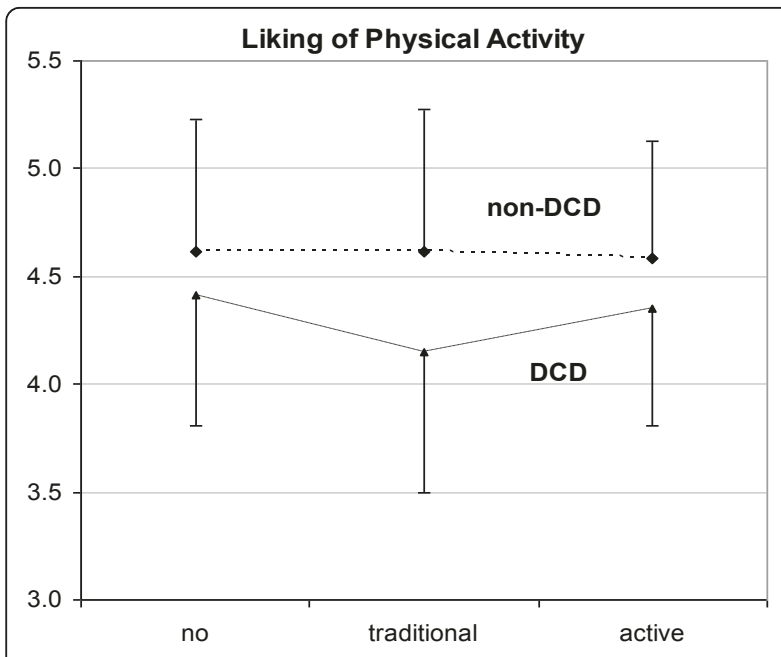

Figure 2 Liking of physical activity ratings in children with and without developmental coordination disorder following 8 weeks with no electronic games, 8 weeks with traditional electronic games and 8 weeks with active VR games

such as Eye and Move (Sony), Wii (Nintendo) and Kinect (Microsoft) have been released, making VR available to households.

Video capture VR (Eye, Kinect) uses a video camera to capture the user's image and movement and embed this into the virtual environment. Whilst it lacks haptic response and single camera systems (Eye) can only track movement in one plane, it requires no head mounted display or exoskeletion thus enabling movement free of encumbrance. Dual camera systems (Kinect) can track in three dimensions. It also provides a mirror view enabling immediate feedback on posture and quality of movement. Users report the interaction is intuitive and natural, with ratings of sense of presence and enjoyment equalling those of expensive laboratory based systems [48].

\section{VR electronic games may lead to improved motor skill and PA outcomes}

A critical feature of video capture VR games is that it requires arm, leg or whole body movement. It may therefore provide gross motor experiences that are not available when interacting using traditional interfaces such as keyboard, mouse or game pad. Video capture VR may thus enable children to play electronic games without the previously observed detrimental physical effects.

We and others have recently reported significant increases in energy expenditure, heart rate and ventilation volume when children played a game with video capture VR compared to a traditional interface $[39,49,50]$. Further, trials are being conducted to determine whether VR games in the home can enhance health outcomes for children [51,52].
VR electronic games can enhance motor skill in adults following brain injury with improved locomotion, upper and lower extremity function [53]. VR has demonstrated some improvements in motor performance in case studies of children with cerebral palsy [54]. Wann et al. [55] argue that VR is an ideal tool for remedial programs involving attention and movement disorders, and discuss its use in the context of stroke patients. VR may be particularly successful for children with DCD as it does not require the child to perform in front of other children. Lack of PA in children with DCD has been attributed to their unwillingness to display their poor skill to others. However, VR electronic games may improve these children's skill by providing gross motor practice involving a high level of visual-spatial integration, but in a context which is private, and provides strong motivation by enjoyment of the game and the challenge of self-competition. However this will only occur if the nature of the movement required is suitable.

Improvements in performance in VR are useful if they lead to improvements in real world performance. Whilst there is no available data on this in children, there is evidence of balance gains from VR training resulting in improved real world balance in elderly subjects undergoing rehabilitation [53]. VR training also leads to greater enjoyment of rehabilitation and improved motor confidence in the real world in adults. This suggests VR games could improve real world motor skill in children and could increase children's confidence, which would be additionally beneficial for children with DCD. However, there is no evidence of the effect of VR on children with DCD.

In our recent pilot study involving 6 children with DCD we found access to video capture VR games for 8 weeks tended to increase motor competence (MAND NDI $8.8 \%, \mathrm{p}=.041)$ as well as accelerometer measured energy expenditure on non school days $(54.3 \% \mathrm{p}=$ .093), compared with access to traditional electronic games in children with DCD and no apparent effect on children without DCD (see Figure 3).

\section{Study Aim}

Therefore the main aim of this study is to determine whether access to new high fidelity active VR electronic games can enhance motor coordination in children with motor impairment. Secondary aims include investigating whether increases in VR performance translate to increases in real world gross motor performance and increases in physical activity, attitudes to physical activity, self confidence and mental health.

\section{Methods/design \\ Design and Aims}

This study will use a cross over randomised controlled trial to assess the impact of active electronic game use 


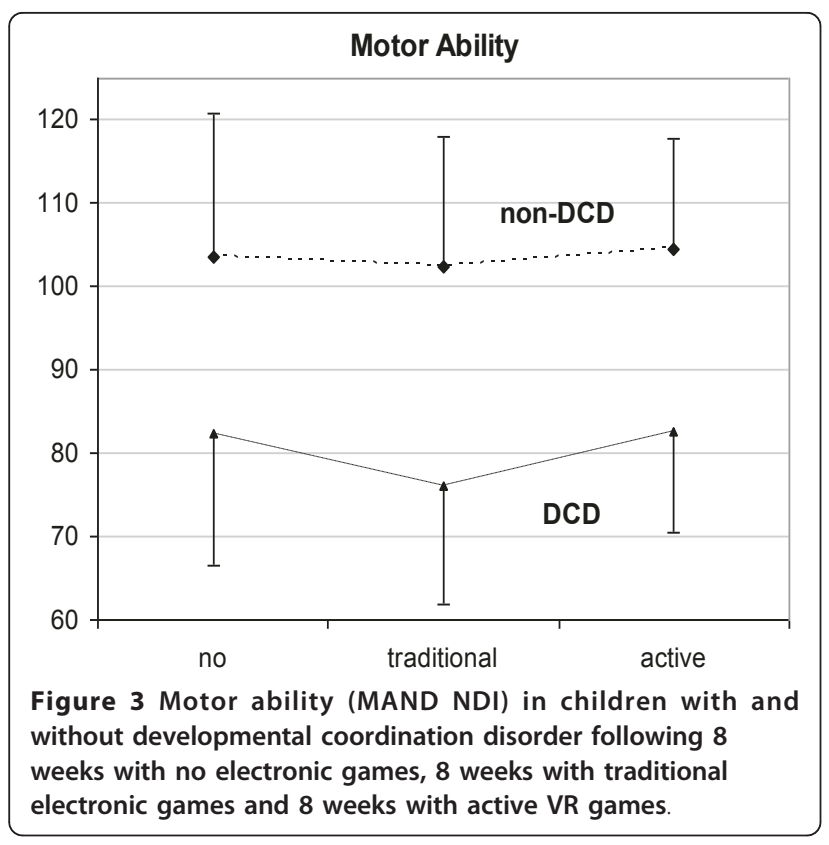

on motor coordination and physical and mental health correlates in children with DCD by:

1) Comparing change in motor coordination over 16 weeks when children use active electronic games or no active electronic games. We hypothesise that motor coordination will improve more when children use active electronic games.

2) Comparing change in parent reports of motor coordination during activities of daily living over 16 weeks when children use active electronic games or no active electronic games. We hypothesise that parent reports of motor coordination will improve more when children use active electronic games.

3) Comparing change in physical activity and sedentary behaviour over 16 weeks when children use active electronic games or no active electronic games. We hypothesise that moderate/vigorous physical activity will increase and sedentary time will decrease more when children use active electronic games.

4) Comparing change in attitudes to physical activity over 16 weeks when children use active electronic games or no active electronic games. We hypothesise that attitudes to physical activity will improve more when children use active electronic games.

5) Comparing change in child reports of mental health over 16 weeks when children use active electronic games or no active electronic games. We hypothesise that mental health will improve more when children use active electronic games.

\section{Sample}

30 children (10-12 years of age) will be recruited by mass media, university and school notices and professional networks. This age group has been selected as they are able to provide detailed information in diary and questionnaires, have a high use of electronic games and are developing physical and mental behaviour patterns prepuberty which may track into adulthood. Children of parents expressing interest will be screened to ensure they are willing to participate after being informed of the full study responsibilities and meet the inclusion and exclusion criteria. Inclusion criteria are: aged 10-12 years at start of study, able to use electronic games on most days and being classified as DCD. DCD status will be assessed using Movement Assessment Battery for Children-2 (MABC-2 [56]. The MABC-2 comprises 8 tasks, three measuring manual dexterity, 3 measuring aiming and catching and 2 measuring balance. Age norms based on a standardisation sample of 1,172 children are used to determine a standard total score $(M=10, S D=3)$. Separate standard scores can be determined for each of the sub-tests. In addition to the total score, a set of qualitative observations allows the examiner to record the child's performance characteristics during the testing. Cut-offs for impairment scores are at or below the 5 th percentile for definite motor difficulties, whilst scores above the 5th percentile but at or below the 15th percentile suggest borderline difficulties. The $15^{\text {th }}$ percentile cut off will be used in this study as this is recommended for research purposes to prevent excluding children with mild DCD [57]. Minimum value of the test-retest reliability of the original MABC is 0.75 and the inter-tester reliability is 0.70 . The original MABC has been found to correlate well with other movement tests $[58,59]$. The MABC-2 will be conducted at a location agreed to by parents, typically the child's home. Children will be excluded if they have a diagnosed disorder likely to impact their study participation, movement or electronic game use (other than developmental coordination disorder), live in a shared care arrangement where the child spends a significant amount of time in different houses and is unable to maintain game access condition, or live remote to the University campus. The child's age and sex will be recorded at baseline along with their experience with electronic games and computers using the Young people's Activity Questionnaire [11].

For power calculations, motor impairment (MABC-2 Total Impairment Score) was estimated at $17+5$ with a minimum effect size of 5 considered important based on effects in prior studies [60]. If the variation in the motor impairment between repeated time points in each individual is normally distributed with standard deviation 5 , and the true effect of game condition is 5 , a study with 30 subjects will reject the null hypothesis that this response difference is zero with probability (power) 0.9027 . The Type I error probability associated with this test of this null hypothesis is 0.01 . 
Volunteers and their parents will be provided with a detailed written description of the study purpose, procedures, risks and benefits and given an opportunity to ask research staff for clarification prior to signing assent (children) and consent (parents) to participate. The study has ethical approval from the Human Research Ethics Committee of Curtin University (approval number HR11/2011).

\section{Intervention and control conditions}

There will be two levels of electronic game access. 'No active electronic games' will involve all active input electronic games being removed from the family home with a contract that active electronic games will be avoided where possible at other locations. Participants will be able to play traditional electronic games using a game pad input during this period. 'Active electronic games' will involve the provision of a Sony PlayStation 3 with Move and Eye input devices and Microsoft Xbox360 with Kinect input device and a range of non-violent games. Children will be contacted regularly during the study and asked to report exposure to electronic games including games played, frequency and duration and level achieved. Children will also be asked about participation in other activities such as sports and hobbies.

A condition period of 16 weeks will allow time for improvements in motor impairment during the active electronic games condition whilst fitting in with school holiday schedules. A within subjects design allows reduced study numbers.

\section{Outcome measures \\ Motor coordination}

Motor coordination will be assessed using the MABC-2 and during a series of tasks performed in a motion analysis laboratory. Detailed kinematic and kinetic data will be collected using a three-dimensional motion analysis system (Vicon; Oxford Metrics, inc.) and two AMTI force plates (Advanced Mechanical Technology, inc.). The large (0.6 * $1.2 \mathrm{~m})$ and small $(0.6 * 0.3 \mathrm{~m})$ force plates are located in the middle of the laboratory directly next to one another and will be operated at $1000 \mathrm{~Hz}$. The 14 camera Vicon motion analysis system will be calibrated to collect data in an approximately $5 \mathrm{~m}^{2}$ area in the middle of the laboratory, running at $250 \mathrm{~Hz}$. Prior to trial performance each child will be fit with the custom full body marker set (seventy two $14 \mathrm{~mm}$ retro-reflective markers). This marker set (Table 1) follows a cluster based protocol and allows the accurate calculation of full body joint kinematics and kinetics complicit with the International Society of Biomechanics recommendations [61,62].

Three tasks drawn from common motor performance tools will be used to assess whole body coordination: running, single leg stance and horizontal jump. Running will be performed using the Test of Gross Motor Development, $2^{\text {nd }}$ edition (TGMD-2; [63]) protocol which involves running over the 10 meter laboratory runway with children instructed to run as fast as they can. Five trials will be performed. Trials will be deemed successful if the child strikes one of the force platforms with their preferred leg. The starting point of the runway will be adjusted in the instance successful foot strike does not occur and the child will not be informed of this requirement to facilitate natural running technique. Single leg stance will be performed using the MAND [46] protocol which involves balancing on their preferred foot with the arms free to move for balance, the unused leg held off the floor with slight knee flexion and pivoting allowed but hopping not. Children will be instructed to stand on the large force plate on their preferred foot for as long as they can or until told to stop. Two trials will be completed with a maximum period of 30 seconds for each trial. Horizontal jump will be performed using the TGMD-2 protocol which involves jumping with feet parallel at start and finish. Children will be instructed to jump as far as they can, while 'sticking' their landing and will perform 5 trials. The take-off will be performed from the middle of the small force plate.

Four tasks drawn from common motor performance tools will be used to assess limb coordination: finger-nose, ball strike, ball kick and ball bounce and catch. Fingernose touch will be performed using the MAND protocol which involves children holding their non preferred arm out in front at shoulder level with the index finger pointed at right angles. The index finger of their preferred hand is used to touch the tip of their nose and the tip of the extended finger moving from supination to pronation. The children will be instructed that it is not a speed test. Ten trials will be performed. Ball strike will be performed using the TGMD-2 Tee ball task which involves a ball being placed on a tee at the height of the child's waist and struck with a bat. The child will be instructed to place their feet shoulder width apart, one on each force plate, facing perpendicular to the intended direction of the $t$-ball strike and then to hit the ball hard. This task will be repeated 5 times. Ball kick will be performed using the TRMD-2 soccer kick task which involves a ball being positioned on the ground slightly ahead (next to the small force plate) and to the preferred side. Children will be instructed to step forward, from the large force plate onto the small force plate, using their non preferred foot and kick the ball as hard as they can towards a goal. The task will be performed 5 times. The ball bounce and catch task is based on the TGMD-2 ball bounce task and requires the participant to stand on the large force plate and bounce the ball onto the small force plate. Children will be instructed to drop the ball with their preferred hand and catch it with both hands. 
Table 1 Three-dimensional motion analysis marker set

\begin{tabular}{|c|c|c|}
\hline Marker & Anatomical location & $\begin{array}{l}\text { Real (R) or } \\
\text { Virtual }(\mathrm{V})^{*}\end{array}$ \\
\hline \multicolumn{3}{|l|}{ Head markers } \\
\hline Eye markers & Placed lateral to canthus of the left and right eyes & $\mathrm{R}$ \\
\hline Ear markers & Placed above the tragus (or concha) of the left and right ears & $\mathrm{R}$ \\
\hline Nose marker & Placed on the tip of the nose & V \\
\hline \multicolumn{3}{|l|}{ Thorax/Back markers } \\
\hline Anterior thorax marker & Sternal notch between the two clavicles & $\mathrm{R}$ \\
\hline $\begin{array}{l}\text { Posterior thorax } \\
\text { markers }\end{array}$ & Placed on the $7^{\text {th }}$ cervical and $6^{\text {th }}$ thoracic vertebrae & $R$ \\
\hline \multicolumn{3}{|l|}{ Pelvis: } \\
\hline Anterior pelvis & Right and left anterior superior iliac crests & $\mathrm{R}$ \\
\hline Posterior pelvis & Right and left posterior superior iliac crest & $\mathrm{R}$ \\
\hline \multicolumn{3}{|l|}{ Lower limbs } \\
\hline Thigh markers & $\begin{array}{l}\text { Three markers set on a t-bar cluster, with the long bar fixed mid-segment along the iliotibial band. The } \\
\text { short bar raps medially onto the quadriceps. }\end{array}$ & $\mathrm{R}$ \\
\hline Tibia markers & $\begin{array}{l}\text { Three markers set on a t-bar cluster, with the long bar fixed mid-segment along the tibia. The short bar } \\
\text { raps laterally towards the fibula. }\end{array}$ & $\mathrm{R}$ \\
\hline Knee markers & Four markers placed on the right and left, medial and lateral femoral condyles & $\mathrm{V}$ \\
\hline Feet markers & Three markers placed on the calcaneus, talus hook and $5^{\text {th }}$ metatarsal & $R$ \\
\hline Ankle markers & Four markers placed on the right and left, medial and lateral malleoli & $\mathrm{V}$ \\
\hline \multicolumn{3}{|l|}{ Upper limbs } \\
\hline Shoulder markers & Right and left, anterior and posterior shoulder markers & $\mathrm{V}$ \\
\hline $\begin{array}{l}\text { Right and left } \\
\text { acromion markers }\end{array}$ & $\begin{array}{l}\text { Three markers placed on the posterior and anterior portion of the lateral border of the acromial plateau, } \\
\text { with one marker placed laterally at the base of the acromioclavicular joint. }\end{array}$ & $\mathrm{R}$ \\
\hline $\begin{array}{l}\text { Right and left upper } \\
\text { arm markers }\end{array}$ & $\begin{array}{l}\text { Three markers set on a t-bar cluster, with the long bar fixed mid-segment on the lateral aspect of the } \\
\text { upper arm. The short bar raps laterally towards the biceps. }\end{array}$ & $\mathrm{R}$ \\
\hline Elbow markers & Right and left, medial lateral epicondyle markers & V \\
\hline Forearm markers & $\begin{array}{l}\text { Three markers placed on the medial and lateral aspect of the distal third of the forearm, with one } \\
\text { marker placed mid segment - between the radius and ulnar, midway up the forearm. }\end{array}$ & $\mathrm{R}$ \\
\hline Wrist markers & Right and left, medial and lateral wrist markers placed on the ulnar and radial styloid processes & V \\
\hline Hand markers & $\begin{array}{l}\text { Three markers, two placed mid-hand medially and laterally. The third marker is placed directly below the } \\
\text { junction between the third metacarpal and third proximal phalange. }\end{array}$ & $\mathrm{R}$ \\
\hline Finger markers & Two smaller markers ( $5 \mathrm{~mm}$ diameter) fixed to the most distal portion of the index finger, finger nail & $\mathrm{R}$ \\
\hline \multicolumn{3}{|l|}{ Equipment } \\
\hline Ball markers & Three markers fixed to each ball; tennis ball, t-ball ball, soccer ball & $\mathrm{R}$ \\
\hline T-ball bat tip & A single marker fixed to the tip of the t-ball bat & $R$ \\
\hline
\end{tabular}

* 'Virtual' markers are removed after one static trial. 'Real' markers remain throughout the motion analysis data collection

Four tasks will be used to assess coordination during active electronic game performance: Move table tennis, Move archery, Kinect table tennis and Kinect soccer penalty kick. For each electronic game task children will be instructed how to perform the task then allowed to practice the task a standard number of times specific to each game. Table tennis will be performed against a computer opponent, with 5 practice points and one game to 11 points repeated on both electronic game consoles. Move archery will be performed against a computer opponent for three trials of 45 seconds. The first set will be used as practice and the final two as assessment trials. The penalty kick trials, performed against a computer opponent, will include one practice trial and three assessment trials.

The primary outcome measures will be the MABC 2 Total Impairment Score, balance as characterised by the length of the path of the centre of mass during the single leg stance trial [28], and upper limb control as characterised by the normalised length of the trajectory of the finger in the finger-nose task [64].

Additionally, movement variability will be assessed using the standard deviation of magnitude and rate of change of kinematics and kinetics across the multiple 
trials of each task; movement smoothness will be assessed using motion pathway rate of change and jerk [65]; movement efficiency will be assessed using time to stability, out of plane motion and path distance; movement sequencing will be assessed with kinematic chain coupling and time of segmental movement onset; and movement accuracy will be assessed using target error distance. Game performance will also be recorded.

\section{Impact of motor coordination on daily living}

Parent report of child coordination difficulties interfering with daily life will be assessed with the revised Developmental Coordination Questionnaire (DCDQ-2007) [66], which assesses motor difficulties in individuals from 4 to 15 years of age. It has 15 -items divided into three subscales: Control During Movement, Fine Motor/Handwriting and General Coordination, and uses a 5 point Likert scale ranging from 1: 'not at all like your child', to 5: 'extremely like your child'. The DCDQ-2007 is selfadministered by parents, comparing their child's motor performance with that of their peers. Using translated versions of the DCDQ-2007 a correlation between test and retest of $r=.94$ was found $(\mathrm{p}<0.001 ; \mathrm{n}=35)$ [67]. Factor analysis has verified the three subscales of the DCDQ-2007 explaining 79\% of the variance [68], and concurrent validity has been demonstrated with a significant correlation of $\mathrm{r}=-.55$ between the total score on the DCDQ-2007 and the original MABC [68].

\section{Physical activity}

Time spent in sedentary, light and moderate to vigorous intensity PA, as well as total movement, will be assessed over 7 days using an Actical accelerometer worn on the hip. The Respironics Actical is the most widely used and validated accelerometer in studies of children and adolescents [69]. Seven days of accelerometer measurement are recommended for the purposes of acceptable measurement of moderate to vigorous PA [70]. Total weekly activity as well as weekend activity and after school weekday activity will be assessed. Children will keep a brief diary recording accelerometer wear times and PA to assist with accelerometer data quality control and processing.

\section{Attitudes to Physical Activity}

Attitudes to PA will be assessed using the revised version [71] of the Physical Activity Enjoyment Scale [72]. Internal consistency, test-retest reliability and construct validity has been demonstrated [71,73,74].

\section{Mental Health}

Harter's Self-Perception Profile for Children [75] will assess self-perceptions across domains of Scholastic Competence, Social Acceptance, Athletic Competence, Physical Appearance and Behavioural Conduct, and it also includes a subscale designed to evaluate global selfworth that assesses self-esteem independent from the competence domains. It has been validated in samples of children from a wide range of cultural backgrounds, including in Australian children and has high levels of internal consistency ranging from .74 to .92 [75].

Spence Children's Anxiety Scale [76] assesses anxiety symptoms in children and consists of six subscales, namely panic attack and agoraphobia, separation anxiety disorder, social phobia, physical injury fears, obsessive compulsive disorder, and generalized anxiety disorder. This self report questionnaire consists of 45 items, 38 assessing specific anxiety symptoms and the remaining six items serve as positive 'filler' items in order to reduce negative response bias. Children are asked to indicate frequency with which each symptom occurs on a four-point scale ranging from Never (scored 0) to Always (scored 3). A total SCAS score is obtained by summing scores of the 38 anxiety symptom items. The scale has high internal consistency for the total score as well as for each subscale, with satisfactory testretest reliability $[77,78]$.

The Short Moods and Feelings Questionnaire [79] is a self report screening tool to assess depression in children and adolescents aged 8 to 16 , that covers areas such as affective, vegetative and cognitive symptoms of depression. This asks the child to rate depressive symptoms in the past 2 weeks on a Likert scale ranging from 0 to 2 , with possible responses of "not true," "sometimes true," and "true". It has 3-week and 3-month test-retest reliabilities of .84 and .80 , respectively [80], high internal consistency [80] and validity with depressive diagnoses derived from standardized diagnostic interviews [81].

\section{Procedure}

Following screening, participants will perform baseline assessments at the research centre after informed consent/ assent from parent and child. Baseline assessments will include all measures described including laboratory biomechanical measures and questionnaires. Participants will be fitted with the accelerometer for wearing at home for the following week and receive check phone calls reminding the child to wear the accelerometer over the next week and to complete the activity diary. Half the participants will then be randomly allocated to the active electronic game conditions and half to the no electronic game (waitlist/normal care) condition by selection of an opaque sealed envelope. Randomisation will be balanced to equal numbers of boys and girls in both initial condition groups. A research officer (RO) will visit the home after one week and collect the accelerometers and instruct parent and child in the game condition. This will involve either removal of all active electronic games or setting up active electronic game equipment and instructing parent and child in its use. Follow-up phone calls will be made regularly to check participation, whether active game equipment is working correctly and electronic game exposure. Towards the end of the each condition the $\mathrm{RO}$ will visit again to set up the accelerometer assessments. After 
16 weeks the child and parent will repeat assessments at the research centre. The RO will visit the participants and set up the other game condition. After 16 weeks in the other game condition the same assessments will occur. The family structure including number, age and sex of siblings will be recorded, and the behaviour of siblings during the trial will be assessed at debriefing interview. Accelerometer assessment will be scheduled to avoid school and public holidays where possible. Individualised reports will be provided to participants.

\section{Trial flow}

Figure 4 provides an overview of the trial flow. Following recruitment, screening and consent and baseline assessments, participants are randomised to an order of electronic game conditions. Participants are setup in their first condition and are assessed at the end of the
16 week condition. Participants are then set up in their second condition for 16 weeks, again with assessment occurring at the end of the condition.

\section{Analysis}

To examine hypothesis 1 (that motor coordination will be improved when children have access to active electronic games) changes from baseline in laboratory biomechanical and MABC-2 outcomes following both conditions will be compared with a repeated measures ANCOVA analysis with sex as a covariate. A critical alpha level of 0.01 will be used to balance type 1 and type 2 errors.

To assess hypotheses 2, 3, 4, 5 (that parent reports of motor coordination in daily living, physical activity and sedentary behaviour, attitudes to physical activity and measures of mental health will improve when children

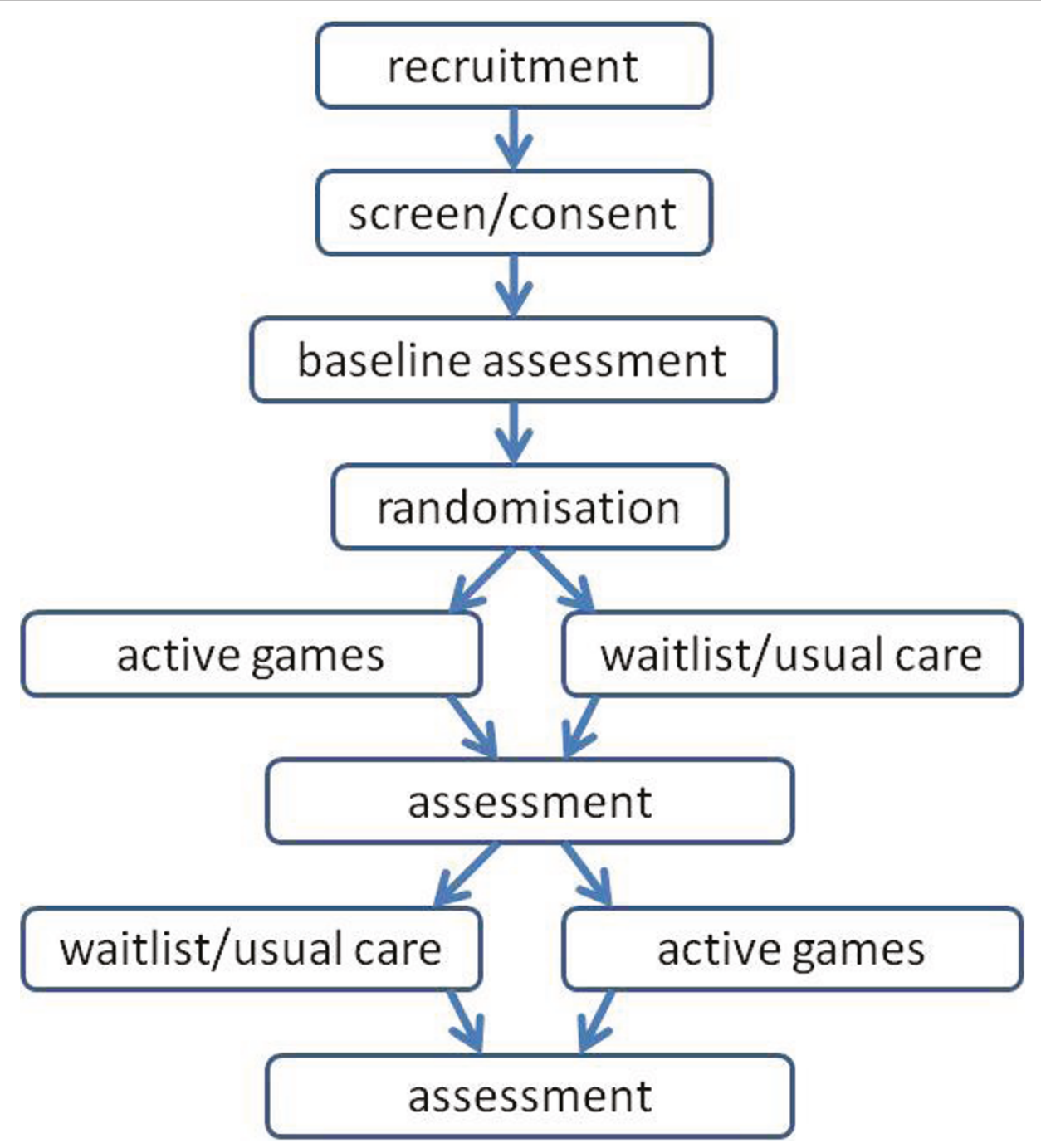

Figure 4 Trial flow chart showing cross-over design and assessment points. 
have access to active electronic games) changes from baseline in outcomes following both conditions will be compared with a repeated measures ANCOVA analysis with sex as a covariate. A critical alpha level of 0.01 will be used to balance type 1 and type 2 errors.

\section{Discussion}

Children's increasing use of computers and especially electronic games may reduce their exposure to the large movement activities necessary for normal motor development and engagement in physical activity. Children with Developmental Coordination Disorder may be especially adversely affected. Persuading children to stop playing computer games is unlikely to be successful. However changing the nature of the movements they use when playing games may reduce the negative impact and potentially provide positive gains in motor ability, motor confidence and overall physical activity levels for children with normal and impaired motor development.

\section{Implications}

This project will be the first to assess the longitudinal impact of providing VR electronic games to children with impaired motor development. The knowledge gained from this study will allow us to understand the potential of active VR games to provide children with the motor development and physical activity necessary for a healthy start to life.

\begin{abstract}
Abbreviations
ANCOVA: analysis of covariance; DCD: developmental coordination disorder; DCDQ: developmental coordination disorder questionnaire; MABC2: movement assessment battery for children - 2; MAND NDI: McCarron assessment of neuromotor disorder neurodevelopmental index; PA: physical activity; RO: research officer; SCAS: Spence children's anxiety scale; TGMD: test of gross motor development; TIS: total impairment scale; VR: virtual reality.
\end{abstract}

\section{Acknowledgements}

This randomised and controlled trial is funded by the National Health and Medical Research Council (NHMRC) of Australia through project grant \#533526. Professor Leon Straker and Doctor Anne Smith are supported by fellowships awarded from the NHMRC. No funding or other input to the study has been received from any electronic game design, manufacture or supply company.

\section{Author details}

${ }^{1}$ School of Physiotherapy, Curtin University, Perth, Australia. ${ }^{2}$ Curtin Health Innovation Research Institute, Curtin University, Perth, Australia. ${ }^{3}$ School of Psychology, Curtin University, Perth, Australia. ${ }^{4}$ School of Human Movement Studies, The University of Queensland, Brisbane, Australia.

\section{Authors' contributions}

All authors have contributed substantially to this protocol. LMS conceived the study, contributed to the study design and drafted the manuscript. ACC, LMJ, DRM, AJS, RAA, CMP and JPP contributed to the study design and revised the manuscript. All authors have read and approved the final manuscript.

\section{Competing interests}

The authors declare that they have no competing interests.

Received: 15 June 2011 Accepted: 18 August 2011

Published: 18 August 2011

\section{References}

1. ABS: Children's participation in cultural and leisure activities, Australia. Canberra, ACT: Australian Bureau of Statistics; 2006.

2. ABS: Household use of information technology, Australia 2001-2002. Canberra, ACT: Australian Bureau of Statistics; 2003.

3. Marshall SJ, Gorely T, Biddle SJH: A descriptive epidemiology of screenbased media use in youth: A review and critique. J Adolesc 2006, 29(3):333-349.

4. Roberts DL, Foehr UG, Rideout V: Generation M: Media in the lives of 8-18 year olds. Menlo Park, CA: The Henry J. Kaiser Family Foundation; 2005.

5. Straker L, Pollock C: Optimizing the interaction of children with information and communication technologies. Ergonomics 2005, 48(5):506-521.

6. Harrison C, Comber C, Fisher T, Haw K, Lewin C, Lunzer E, McFarlane A, Mavers D, Scrimshaw P, Somekh B, Watling R: ImpaCT2: The impact of information and communication technologies on pupil learning and attainment. A report to the Department for Education and Skills. ICT in school research and evaluation series - No. 9. London: British Educational Communications and Technology Agency; 2002.

7. Moseley D, Mearns N, Tse H: Using computer at home and in the primary school: Where is the value added? Educational and Child Psychology 2001, 18:31-46.

8. Heft TM, Swaminathan S: The effects of computers on the social behavior of preschoolers. J Res Child Edu 2002, 16:162-174.

9. Villani SS: Impact of media on children and adolescents: A 10-year review of the research. J Am Acad Child Adolesc Psychiatry 2001, 40(4):392-401.

10. Barrero $M$, Hedge $A$ : Computer environments for children: a review of design issues. Work 2002, 18(3):227-237.

11. Harris C, Straker L: Survey of physical ergonomics issues associated with school children's use of laptop computers. Int J Ind Ergon 2000, 26(3):337-346.

12. Straker $L$, Briggs $A$, Greig A: The effect of individually adjusted workstations on upper quadrant posture and muscle activity in school children. Work 2002, 18(3):239-248.

13. White FA, Hayes BK, Livesey DJ: Developmental psychology: From infancy to adulthood Sydney: Pearson Education Australia; 2005.

14. McKenzie TL, Alcaraz JE, Sallis JF, Faucetter FN: Effects of a physical education program on children's manipulative skills. J of Teaching in Phys Ed 1998, 17(3):327-341.

15. Yuji H: Computer games and information-processing skills. Percept Mot Skills 1996, 83(2):643-647.

16. Whitcomb GR: Computer games for the elderly. Proceedings of the Conference on Computers and the Quality of Life 1990; Washington, USA Association for Computing Machinery, ACM, New York, NY, USA; 1990, 112-115.

17. Rosser JC, Lynch PJ, Cuddihy L, Gentile DA, Klonsky J, Merrell R: The impact of video games on training surgeons in the 21st century. Arch Surg 2007, 142(2):181-186.

18. Straker LM, Pollock CM, Zubrick SR, Kurinczuk JJ: The association between information and communication technology exposure and physical activity, musculoskeletal and visual symptoms and socio-economic status in 5-year-olds. Child Care Health Dev 2006, 32(3):343-351.

19. Polatajko HJ, Fox AM, Missiuna C: An international consensus on children with developmental coordination disorder. Can J Occup Ther 1995, 62:3-6.

20. Wilson PH: Practitioner review: approaches to assessment and treatment of children with DCD: an evaluative review. J Child Psychol Psychiatry 2005, 46(8):806-823.

21. Piek JP, Dyck M: Sensory-motor deficits in children with developmental coordination disorder, attention deficit hyperactivity disorder \& autistic disorder. Hum Mov Sci 2004, 23(3):475-488.

22. Wilson $\mathrm{PH}, \mathrm{McK}$ Kenzie $\mathrm{BE}$ : Information processing deficits associated with developmental coordination disorder: A meta-analysis of research findings. J Child Psychol Psychiatry 1998, 39(6):829-840. 
23. Piek JP, Skinner RA: Timing and force control during a sequential tapping task in children with and without motor coordination problems. J Int Neuropsychol Soc 1999, 5(4):320-329.

24. Rivilis I, Hay J, Cairney J, Klentrou P, Liu J, Faught BE: Physical activity and fitness in children with developmental coordination disorder: a systematic review. Res Dev Disabil 2011, 32(3):894-910.

25. Hay JA, Hawes R, Faught BE: Evaluation of a screening instrument for developmental coordination disorder. J Adolesc Health 2004, 34(4):308-313.

26. Hillier S: Intervention for children with developmental coordination disorder: A systematic review. The Internet Journal of Allied Health Sciences and Practice 2007, 5(3)

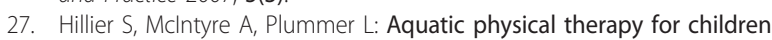
with developmental coordination disorder: A pilot randomized controlled trial. Phys Occup Ther Pediatr 2010, 30(2):111-124.

28. Tsai CL: The effectiveness of exercise intervention on inhibitory control in children with developmental coordination disorder: using a visuospatial attention paradigm as a model. Res Dev Disabil 2009, 30(6):1268-1280

29. Harter S: Effectance motivation reconsidered. Hum Dev 1978, 21:34-64.

30. Harter S: A model of intrinsic mastery motivation in children: Individual differences and developmental change. In Minnesota Symposia on Child Psychology. Volume 14. Edited by: Collins WA. Hillsdale, NJ: Erlbaum; 1981

31. Doganis $G$, Theodorakis $Y$ : The influence of attitude on exercise participation. In European Perspectives on Exercise and Sport Psychology. Edited by: Biddle S. Champaign, IL: Human Kinetics; 1995:

32. Abbott RA, Macdonald D, Mackinnon L, Stubbs CO, Lee AJ, Harper C, Davies PSW: Healthy Kids Queensland Survey 2006 - Summary Report. Brisbane, QLD; 2007

33. Biddle SJ, Gorely T, Stensel DJ: Health-enhancing physical activity and sedentary behaviour in children and adolescents. J Sports Sci 2004, 22(8):679-701.

34. Cairney J, Hay JA, Faught BE, Hawes R: Developmental coordination disorder and overweight and obesity in children aged 9-14 y. Int J Obes (Lond) 2005, 29(4):369-372.

35. Poulsen AA, Ziviani JM, Cuskelly M: Perceived freedom in leisure and physical co-ordination ability: Impact on out-of-school activity participation and life satisfaction. Child Care Health Dev 2007, 33(4):432-440

36. Piek JP, Dworcan M, Barrett NC, Coleman R: Determinants of self worth in children with and without DCD. International Journal of Disability, Development and Education 2000, 47(3):259-272.

37. Skinner RA, Piek JP: Psychosocial implications of poor motor coordination in children and adolescents. Hum Mov Sci 2001, 20(1):73-94.

38. Francis M, Piek JP: The effects of perceived social support and self-worth on depressive symptomatology in children with and without Developmental Coordination Disorder. 38th APS Annual Conference: 2-5 October 2003 2003; Perth, Western Australia 2003.

39. Straker $L$, Abbott R: Effect of screen-based media on energy expenditure and heart rate in 9- to 12-year-old children. Pediatr Exerc Sci 2007 19(4):459-471.

40. Straker L, Pollock C, Piek J, Abbott R, Skoss R, Coleman J: Active-input provides more movement and muscle activity during electronic game playing by children. Int J Hum Comput Interact 2009, 25(8):713-728.

41. Li X, Atkins MS: Early childhood computer experience and cognitive and motor development. Pediatrics 2004, 113(6):1715-1722.

42. Marshall SJ, Biddle SJ, Gorely T, Cameron N, Murdey I: Relationships between media use, body fatness and physical activity in children and youth: a meta-analysis. Int J Obes Relat Metab Disord 2004, 28(10):1238-1246.

43. Motl RW, McAuley E, Birnbaum AS, Lytle LA: Naturally occurring changes in time spent watching television are inversely related to frequency of physical activity during early adolescence. J Adolesc 2006, 29(1):19-32.

44. Rey-Lopez JP, Vicente-Rodriguez G, Biosca M, Moreno LA: Sedentary behaviour and obesity development in children and adolescents. Nutr Metab Cardiovasc Dis 2008, 18(3):242-251.

45. Straker L, Coleman J, Abbott R, Piek J, Pollock C: A pilot study on the impact of electronic games on physical activity in children. CybErg 2008, the 5th International Cyberspace Conference on Ergonomics Sarawak, Malaysia; 2008
46. McCarron L: McCarron assessment of neuromotor development: Fine and gross motor abilities. 3 edition. TX, USA: Common Market Press; 1997

47. Gomes A: Pre-adolescent participation in physical activity: Investigating the role of socialization factors. Perth, WA.: Curtin University of Technology; 1999.

48. Weiss PL, Rand D, Katz N, Kizony R: Video capture virtual reality as a flexible and effective rehabilitation tool. J Neuroeng Rehabil 2004, 1(12).

49. Lanningham-Foster $L$, Jensen $T B$, Foster RC, Redmond AB, Walker BA, Heinz D, Levine JA: Energy expenditure of sedentary screen time compared with active screen time for children. Pediatrics 2006, 118(6):1831-1835.

50. Maddison R, Mhurchul CN, Jull A, Jiang Y, Prapavessis H, Rodgers A: Energy expended playing video console games: An opportunity to increase children's physical activity? Pediatr Exerc Sci 2007, 19(3):1-24.

51. Maddison R, Foley L, Ni Mhurchu C, Jiang Y, Jull A, Prapavessis $H$, Hohepa M, Rodgers A: Effects of active video games on body composition: a randomized controlled trial. Am J Clin Nutr 2011.

52. Straker LM, Abbott RA, Piek JP, Pollock CM, Davies PS, Smith AJ: Rationale, design and methods for a randomised and controlled trial to investigate whether home access to electronic games decreases children's physical activity. BMC Public Health 2009, 9:212.

53. Sveistrup $\mathrm{H}$ : Motor rehabilitation using virtual reality. J Neuroeng Rehabil 2004, 1(1):10.

54. Reid DT: The use of virtual reality to improve upper-extremity efficiency skills in children with cerebral palsy: A pilot study. Technol Disabil 2002, 14:53-61.

55. Wann JP, Rushton SK, Smyth M, Jones D: Rehabilitative environments for attention and movement disorders. Commun ACM 1997, 40(8):49-52.

56. Henderson SE, Sugden DA, Barnett AL: Movement Assessment Battery for Children-2 London, UK: Harcourt Assessment; 2007.

57. Gueze RH, Jongmans MJ, Schoemaker MM, Smits-Engelsman BC: Clinical and research diagnostic criteria for developmental coordination disorder: a review and discussion. Hum Mov Sci 2001, 20(1-2):7-47.

58. Laszlo Jl, Bairstow PJ: Control of skilled movement: processes underlying acquisition and performance. In Perceptual-motor behaviour: Developmental assessment and therapy. Edited by: Laszlo Jl, Bairstow PJ. London: Holt, Rinehart 1985:11-124.

59. Smits-Engelsman BCM, Henderson SE, Michels CGJ: The assessment of children with Developmental Coordination Disorders in the Netherlands: The relationship between the Movement Assessment Battery for Children and the Körperkoordinations Test für Kinder. Hum Mov Sci 1998, 17(4-5):699-709.

60. Niemeijer AS, Smits-Engelsman BC, Schoemaker MM: Neuromotor task training for children with developmental coordination disorder: a controlled trial. Dev Med Child Neurol 2007, 49(6):406-411.

61. Wu G, Siegler S, Allard P, Kirtley C, Leardini A, Rosenbaum D, Whittle M, D'Lima DD, Cristofolini L, Witte H, Schmid O, Stokes I: ISB recommendation on definitions of joint coordinate system of various joints for the reporting of human joint motion- part I: ankle, hip and spine. J Biomech 2002, 35:543-548.

62. Wu G, van der Helm FCT, Veeger HEJ, Makhsous M, Van Roy P, Anglin C, Nagels J, Karduna AR, McQuade K, Wang X, Werner B, Buchholz B: ISB recommendation on definitions of joint coordinate systems of various joints for the reporting of human joint motion - Part II: Shoulder, elbow, wrist and hand. J Biomech 2005, 38:981-992.

63. Ulrich DA: Test of Gross Motor Development - 2nd edition. Examiner's Manual. Second edition. Austin TX: Pro-Ed; 2000.

64. Ameratunga $D$, Johnston L, Burns $Y$ : Goal-directed upper limb movements by children with and without DCD: A window into perceptuo-motor dysfunction? Physiother Res Int 2004, 9(1):1-12.

65. Chang JJ, Wu TI, Wu WL, Su FC: Kinematical measure for spastic reaching in children with cerebral palsy. Clin Biomech 2005, 20(4):381-388.

66. Wilson BN, Crawford SG: The Developmental Coordination Disorder Questionnaire 2007 (DCDQ'07). Administrative manual for the DCDQ'07 with psychometric properties Calgary, Canada: Alberta Health Services; 2010.

67. Tseng MH, Fu CP, Wilson BN, Hu FC: Psychometric properties of a Chinese version of the Developmental Coordination Disorder Questionnaire in community-based children. Res Dev Disabil 2010, 31(1):33-45.

68. Wilson BN, Crawford SG, Green D, Roberts G, Aylott A, Kaplan BJ: Psychometric properties of the revised Developmental Coordination Disorder Questionnaire. Phys Occup Ther Pediatr 2009, 29(2):182-202. 
69. Puyau MR, Adolph AL, Vohra FA, Butte NF: Validation and calibration of physical activity monitors in children. Obes Res 2002, 10(3):150-157.

70. Trost SG, Pate RR, Freedson PS, Sallis JF, Taylor WC: Using objective physical activity measures with youth: how many days of monitoring are needed? Med Sci Sports Exerc 2000, 32(2):426-431.

71. Motl RW, Dishman RK, Saunders R, Dowda M, Felton G, Pate RR: Measuring enjoyment of physical activity in adolescent girls. Am J Prev Med 2001, 21(2):110-117.

72. Kendzierski D, DeCarlo KJ: Physical Activity Enjoyment Scale: Two validation studies. J Sport Exerc Psychol 1991, 13(1):50-64.

73. Dishman RK, Motl RW, Saunders R, Felton G, Ward DS, Dowda M, Pate RR: Enjoyment mediates effects of a school-based physical-activity intervention. Med Sci Sports Exerc 2005, 37(3):478-487.

74. Moore J, Yin Z, Hanes J, Duda J, Gutin B, Barbeau P: Measuring enjoyment of physical activity in children: Validation of the Physical Activity Enjoyment Scale. J Appl Sport Psychol 2009, 21(S1):116-129.

75. Harter S: Manual for the self-perception profile for children: Revision of the Perceived Competence Scale for Children Denver, USA: University of Denver; 1985.

76. Spence SH: Structure of anxiety symptoms among children: a confirmatory factor-analytic study. J Abnorm Psychol 1997, 106(2):280-297.

77. Essau CA, Muris P, Ederer EM: Reliability and validity of the Spence Children's Anxiety Scale and the Screen for Child Anxiety Related Emotional Disorders in German children. J Behav Ther Exp Psychiatry 2002, 33(1):1-18.

78. Spence SH: A measure of anxiety symptoms among children. Behav Res Ther 1998, 36(5):545-566.

79. Angold A, Costello E, Messer S: Development of a short questionnaire for use in epidemiological studies of depression in children and adolescents. Int J Methods Psychiatr Res 1995, 5:237-249.

80. Sund AM, Larsson B, Wichstrom L: Psychosocial correlates of depressive symptoms among 12-14-year-old Norwegian adolescents. J Child Psychol Psychiatry 2003, 44(4):588-597.

81. Kent $L$, Vostanis P, Feehan C: Detection of major and minor depression in children and adolescents: evaluation of the Mood and Feelings Questionnaire. J Child Psychol Psychiatry 1997, 38(5):565-573.

\section{Pre-publication history}

The pre-publication history for this paper can be accessed here: http://www.biomedcentral.com/1471-2458/11/654/prepub

doi:10.1186/1471-2458-11-654

Cite this article as: Straker et al:: Rationale, design and methods for a randomised and controlled trial of the impact of virtual reality games on motor competence, physical activity, and mental health in children with developmental coordination disorder. BMC Public Health 2011 11:654.

\section{Submit your next manuscript to BioMed Central and take full advantage of:}

- Convenient online submission

- Thorough peer review

- No space constraints or color figure charges

- Immediate publication on acceptance

- Inclusion in PubMed, CAS, Scopus and Google Scholar

- Research which is freely available for redistribution 